\title{
Development Value and Future Trend of Urban Underground Street
}

\author{
Pei Zhang \\ GSST, Kumamoto University, Kumamoto City, Japan \\ Email: coocoobar@foxmail.com
}

How to cite this paper: Zhang, P. (2019) Development Value and Future Trend of Urban Underground Street. Current Urban Studies, 7, 20-34.

https://doi.org/10.4236/cus.2019.71002

Received: January 29, 2019

Accepted: February 22, 2019

Published: February 25, 2019

Copyright $\odot 2019$ by author(s) and Scientific Research Publishing Inc. This work is licensed under the Creative Commons Attribution International License (CC BY 4.0).

http://creativecommons.org/licenses/by/4.0/

\section{c) (i) Open Access}

\begin{abstract}
Underground street refers to a street built under a busy business district or a crowding center in a city, providing underground sidewalks for urban residents, opening shops and arranging various service facilities on both sides. Starting with the definition of urban underground street, this paper analyses the origin, classification, composition, development value and future trend of underground street, and holds that reasonable proportion should be maintained in the area of each component of underground street. The main development value of underground street lies in saving land and alleviating traffic pressure. 3D, urban complex, humanistic design and tourist attractions are future development trends of urban underground street.
\end{abstract}

\section{Keywords}

Underground Street, Value, Trend, Recreation

\section{Introduction}

Since the world's first subway was built in London in 1863, the development of underground space in developed countries has gone through quite a long period of time. The development and utilization of underground space in developed countries extends naturally from large buildings to underground streets, and then to complex underground complexes and underground cities. The underground streets have played an important role in the reconstruction of the old city center. Since the 1950s, some big cities in developed countries have begun to build underground streets in large quantities, especially in Japan and Canada, because of their concentrated population, dense buildings and shortage of land, especially in the central business district. Japan is the earliest country in the world to develop underground streets. In 1930, Japan built shops on both sides 
of the underground passage of Nagano Station on the Tokyo Metro, which is said to be the earliest source of underground streets. Since then, Japan has opened underground streets at Japanese bridges and Ginza in Tokyo. Japan is also the country with the largest number of underground streets in the world. There are more than 100 underground streets in Japan, with a total floor area of nearly 1.3 million square meters. Osaka has the largest number of underground streets in Japan. The underground streets receive 3.2 million customers every day. The Sampani Underground Street in Osaka is the largest in Japan, with an area of 80,000 square meters and more than 300 stores. In addition, the Underground Street of Montreal, Canada is exactly an underground city. It was built in 1962 and was originally an underground shopping mall. However, it has become a huge consumer shopping center. The whole underground city is connected with 2 bus terminals, 10 subway stations, 1200 offices, 1615 households, 7 hotels, 1600 shops, 2 department stores, 200 restaurants, 40 banks, 30 cinemas, 3 exhibition centers, 1 church, and the Olympic Park, the University of Montreal, the Mongcheng Campus of the University of Quebec, etc. The underground city has a wide range of shops, including bookstores, cafes, restaurants, clothing stores, boutiques, bakeries, supermarkets and so on. There are almost all underground stores on the ground.

\section{The Concept and Origin of Underground Street}

The origin of underground streets can be traced back to 1910. The French architect Eugene Henard put forward the concept of Multi-Level-Street in order to solve the problem of interference between pedestrians and vehicles in cities and to obtain highly intensive use of land. The original idea is to use the ground floor as a space for carriages and cars, the first underground floor as a pedestrian track and tram tracks and stairs leading to the ground floor, the second underground floor as a service lane, the third underground floor as a city subway system, and the fourth underground floor as a garbage and commodity transport lane (Gideon \& Toshio, 1996). The definition of underground street in the Basic Principles of Underground Street (1974) of Japan is as follows: In the area of public land such as roads or station squares (including built roads or station squares), underground facilities consisting of public underground walkways (including the access outside the gate of underground stations and station halls) and shops and offices facing public underground walkways (if with public underground parking lots) are integrated. The public underground parking lot is also included in the joint construction. However, in the shops, offices and other facilities facing the underground walkway, the stations, machinery rooms and other movable or temporary facilities specially used for the management and operation of public facilities are not within the scope of the objects of the underground street (Liu \& Shen, 2017). However, the English expression of underground street in Japanese academia is underground town. From its meaning, we can see that from the beginning, Japan expected underground street to become a 
"town" in the expansion of underground life, not a simple "street" concept.

The definition of underground street in European and American countries is slightly different from that in Japan. London calls the subway underground directly, and the expressions derived there from are Underground Street, Underground Arcade, Underground Shopping Center, Underground City, etc. The English dictionary generally interprets the underground street as "a network of tunnels connecting buildings below the street, which connect office buildings, shopping malls, subway stations, theatres and other attractions in series". It can be seen from the literal meaning that Europe and the United States emphasize their business activities when they understand the underground street. As a series of connected underground spaces, underground streets can be defense shelters, living, working or shopping.

Although there are some differences in the definition of underground street in different countries and regions, it is generally accepted that it is developed from underground pedestrian passage in academic circles. Similar to the ground pedestrian overpass, the original construction of underground streets was mainly to alleviate the pressure of mixed flow of pedestrians and vehicles on the ground. As a way for pedestrians to cross the road, there were no shops or other facilities in the interior of the underground street at first, but since it was found that the underground street could create commercial benefits, people set up advertisements, windows and advertising light boxes on both sides of the pedestrian corridor. From then on, the underground commerce combined with the underground corridor and gradually evolved into the underground street (Figure 1).

Urban traffic and urban renewal have further affected the further development of urban underground streets. Since the 1960s, the contradiction between man and land in urban central areas of developed countries has become the focus of urban renewal and transformation. Practice has proved that the development and utilization of urban underground streets has become an effective way to solve the contradictions of environment, population and transportation in urban central areas. In 1983, the United Nations had identified "underground space" as an important natural resource. The Tokyo Declaration was adopted at the International Academic Conference on Urban Underground Space held in Tokyo in 1991, which put forward that "the 21st century is the century of human development and utilization of underground space". The theme of the 7th International Symposium on Underground Space, held in Montreal in 1997, is
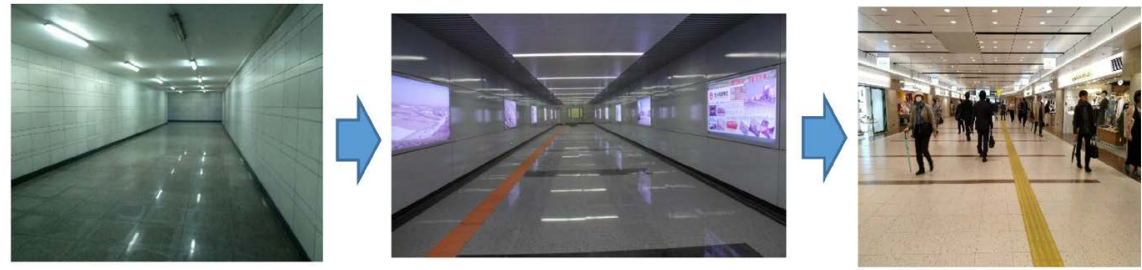

Figure 1. Evolution of underground street. 
"Tomorrow-Indoor City". In 1998, an international academic conference on underground cities was held in Moscow. With the rapid development of underground space utilization, underground streets in various countries have the opportunity to mature and form a multi-functional urban complex. Therefore, the underground street is developed through the development of urban underground space, which is located in the urban central area as a complementary product of urban functions. The development of underground space in various countries shows that it is inevitable for the world to ask for land and space underground. The development and utilization of urban underground space has become a worldwide trend of development (Zhou et al., 2006).

\section{Categories of Urban Underground Streets}

There are many methods to classify urban underground streets. It is common to classify urban underground streets according to their layout shape and development area scale.

\subsection{According to Spatial Form}

Street-type underground street: mainly in the city avenue underground, with access to the avenue on both sides of the underground pedestrian street, sometimes with subway or underpass linking surrounding underground space. Each functional space is connected in series by a linear street, so that the plane is roughly arranged in a line, which may be a straight line, curve or broken line. Street-type underground streets are mostly built in the space between the subway and the ground. Stores are usually located on both sides of the central passage of underground street. Sometimes the scope of street underground street is not limited to the area under an avenue, but through the connection of underground space, spanning two to three blocks, and forming L-shaped, T-shaped layout. If such underground streets are jointly developed with underground pedestrian passages, it will be possible to form an underground pedestrian network (Figure 2).

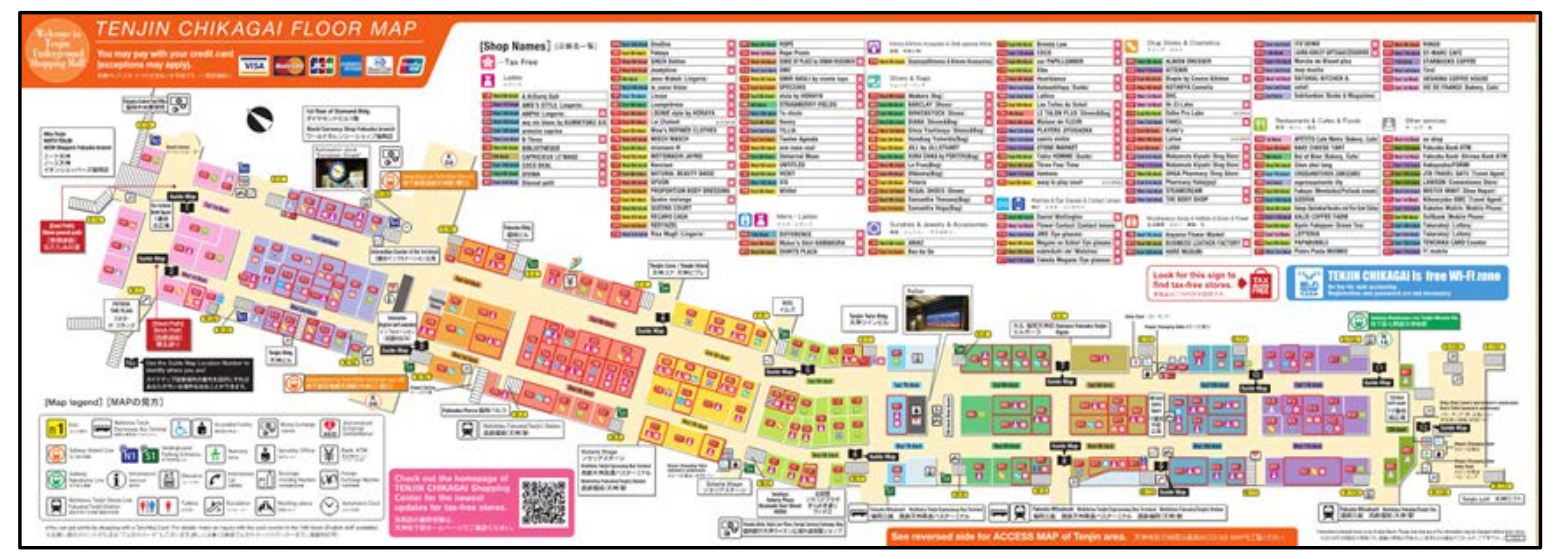

Figure 2. Linear street-type: Tenjin Underground Street, Fukuoka, Japan. Source: Tenjin official website. URL: http://www.tenchika.com/. 
Square-type underground street: often located in the front of the station square or city square underground, which connects with the ground and transportation hub by entrance and exit, vertical channel and ground subsidence square. Square-type underground streets are usually large in scale and have relatively free shop layout. Unlike street-type underground streets, shops are located at both ends of the corridor, but mostly in lobby layout. In addition, with the common development of the ground environment, more functional integration and higher efficiency can be formed between the ground and underground in the landscape (Figure 3).

Compound underground street: In fact, it is a combination of several underground streets, usually a square underground street combined with several cross-block underground streets formed by underground commercial belt. Compound underground street is a form of underground street only when it has matured and developed, and its appearance also represents that the city has formed underground street system. In the three metropolitan areas of Japan: Tokyo, Osaka and Nagoya, and Taipei, China, there are some successful examples of compound underground streets. Figure 4 is the street map of Nagoya Sakae Underground Street, Japan.

\subsection{According to the Scale}

According to the different scale, it can be divided into small, medium and large urban underground streets. The standards of different countries and regions are different. For example, according to the author's field research, Japan is based on

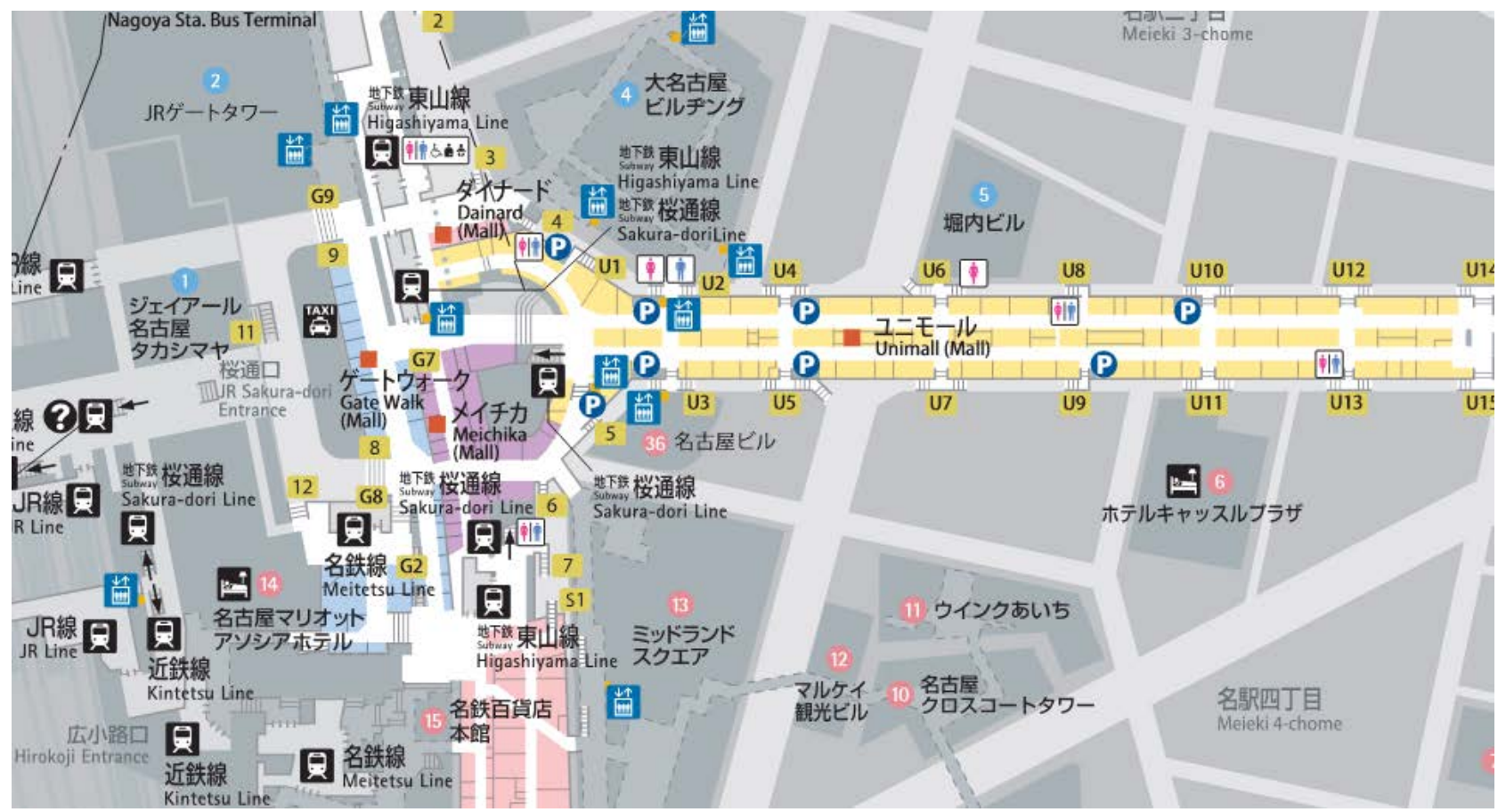

Figure 3. Square-type: Nagoya Station Underground Street, Japan. Source: Nagoya official website. URL: http://www.unimall.co.jp/. 


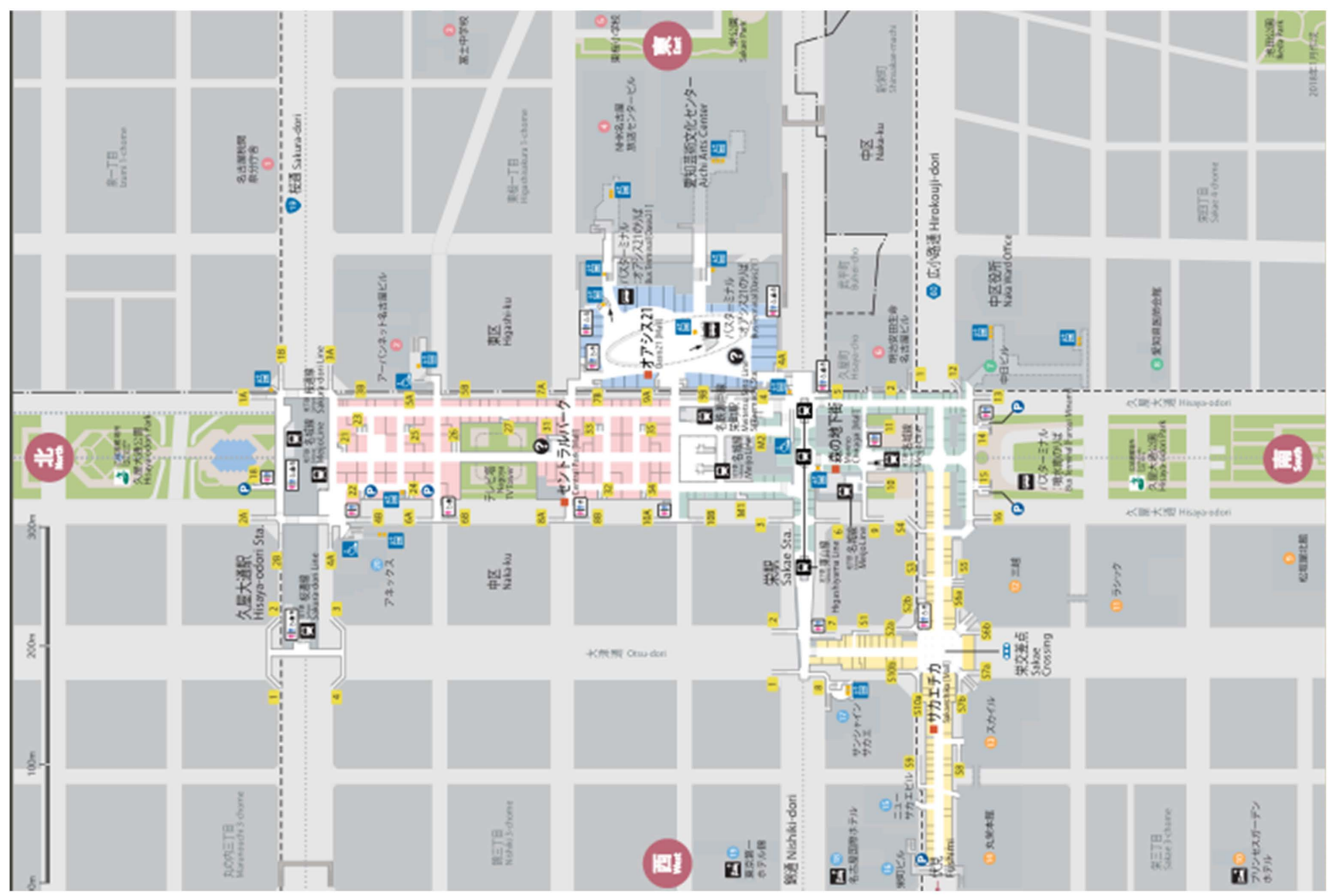

Figure 4. Compound underground street: Nagoya Sakae Underground Street, Japan. Source: Nagoya official website. URL: http://www.unimall.co.jp/.

the number and area of stores as a basis for classification. Small underground street: area of less than 3000 square meters, less than 50 shops; Medium underground street: area of 3000 - 10,000 square meters, 50 - 100 shops; Large underground street: area of more than 10,000 square meters, more than 100 shops.

\section{Main Composition of Urban Underground Street}

Underground street is different from underground shopping mall. Underground shopping mall is a single-function underground commercial facility. It has no "street" traffic function. Underground street is a complex of traffic function and commercial function. There are some differences in planning and design between them. Underground shopping malls are designed according to underground commercial buildings, while underground streets must be designed according to the requirements of underground pedestrian system and underground commercial buildings.

Underground streets are centered on people gathering points in cities (such as urban transportation hub, business center, etc.). They evacuate people through underground walkways, and set up necessary shops, convenient offices, disaster prevention facilities in underground walkways. When necessary, underground 
garages are also built to form underground complexes. Therefore, the underground street is composed of three basic parts, namely underground pedestrian traffic, underground business and underground supporting parts (including equipment rooms).

Firstly, underground pedestrian traffic section, which includes the passages and squares in the underground street besides shops, crosswalk, connecting passages between underground stations, entrances and exits, staircases and escalators and other internal vertical traffic facilities.

Secondly, underground business section, which includes shops, restaurants, entertainment facilities, office, exhibition hall, bank, post office and other business facilities.

Thirdly, underground supporting parts, which includes underground motor vehicle operation and storage system, such as underground parking lot, expressway, etc.; underground street internal equipment system, refers to ventilation, air conditioning, power distribution, water supply and drainage equipment used for underground street itself; auxiliary room, refers to central control room, disaster prevention center, office, auxiliary rooms such as offices, warehouses and toilets.

There is no uniform standard in the world for the proportion of components. Taking Japan as an example, the construction standards of Japan after 1973 stipulate that the area of shops in underground streets should not be larger than that of public corridors, and that the sum of shops and corridors is approximately equal to the area of parking lots, which can also be expressed by formulas as follows:

$$
\begin{gathered}
A \leq B \\
A+B \cong C
\end{gathered}
$$

In the formula, $A$-store area;

$B$-passage area;

$C$-parking area.

For example, in the underground street of Kyoto, Japan, the proportion of pedestrian walkways in the total building area is as high as $50 \%$, the earlier the construction, the lower the proportion (Table 1) (Tong, 2005).

Table 1. Comparison of the proportion of underground streets in 6 major cities in Japan.

\begin{tabular}{ccccccccccc}
\hline \multirow{2}{*}{ Year } & \multirow{2}{*}{ City } & floor space & \multicolumn{2}{c}{ Passage } & \multicolumn{2}{c}{ Shop } & \multicolumn{2}{c}{ Parking lot } & \multicolumn{2}{c}{ Machine room, etc. } \\
\cline { 4 - 10 } & & $\mathrm{m}^{2}$ & area $/ \mathrm{m}^{2}$ & $\%$ & area $/ \mathrm{m}^{2}$ & $\%$ & area $/ \mathrm{m}^{2}$ & $\%$ & area $/ \mathrm{m}^{2}$ & $\%$ \\
\hline 1964 & Yokohama & 89,662 & 20,047 & 22.4 & 26,938 & 30.0 & 34,684 & 38.7 & 7993 & 8.9 \\
1965 & Kobe & 34,252 & 9650 & 28.2 & 13,867 & 40.5 & - & 0 & 10,735 & 31.3 \\
1973 & Osaka & 95,798 & 36,075 & 37.6 & 42,135 & 44.0 & - & 0 & 17,588 & 18.4 \\
1974 & Nagoya & 168,968 & 46,979 & 27.8 & 46,013 & 27.2 & 44,961 & 26.6 & 31,015 & 18.4 \\
1974 & Tokyo & 223,083 & 45,116 & 20.3 & 48,308 & 21.6 & 91,523 & 41.0 & 38,138 & 17.1 \\
1980 & Kyoto & 21,038 & 10,520 & 50.0 & 8292 & 39.4 & - & 0 & 2226 & 10.6 \\
\hline
\end{tabular}

Source: Tong. Underground space and urban modernization, 2005. 
There are also differences in the composition of underground streets for different scales. The reasonable proportion of each component of underground streets in area should be maintained, reflecting the primary and secondary relationship of each function of underground streets. A reasonable proportional relationship should be maintained among the business, transportation and supporting parts. Any part too large or too small will have adverse effects on use, efficiency and safety. If the business area is too small, the investors' income will be reduced; but if the business area is pursued blindly, the pedestrian corridor area will be narrower, which will affect the overall grade and taste of commercial projects, and there is potential insecurity. For example, the area and proportion of the commercial components in the Japanese underground street are shown in the table below (Table 2).

As can be seen from the above table, the average business area of the underground street accounts for $49 \%$ of the total buildings, the traffic area accounts for $32 \%$ of the total buildings, the auxiliary area accounts for $13 \%$ of the total buildings, and the ratio is about 4:3:1. In fact, the recreational space of the underground street covers the business area, most of the traffic area and a small part of the auxiliary area (such as toilets). In view of this, the underground streets in Japan really guarantee the space needs of recreational activities in design. This point is worthy of reference in the development and utilization of recreational resources of underground streets. It is necessary to reflect the characteristics of recreational functions from the spatial scale.

Table 2. Comparison of business area and traffic area of underground street in Japan.

\begin{tabular}{|c|c|c|c|c|c|c|c|}
\hline \multirow{2}{*}{ Name } & \multirow{2}{*}{\multicolumn{2}{|c|}{ Total }} & \multicolumn{2}{|c|}{ Store area $\mathrm{m}^{2}$} & \multicolumn{2}{|c|}{ Traffic area $\mathrm{m}^{2}$} & \multirow{2}{*}{$\begin{array}{c}\text { Auxiliary } \\
\text { area } \mathrm{m}^{2}\end{array}$} \\
\hline & & & Shop & Lounge & Level & Vertical & \\
\hline \multirow{2}{*}{ YAESU, Tokyo } & area & 35,584 & 18,352 & 1145 & 11,029 & 1732 & 3326 \\
\hline & $\%$ & $100 \%$ & $52 \%$ & $3 \%$ & $31 \%$ & $5 \%$ & $9 \%$ \\
\hline \multirow{2}{*}{ Diamor, Osaka } & area & 29,480 & 14,160 & 1368 & 8840 & 1008 & 4104 \\
\hline & $\%$ & $100 \%$ & $48 \%$ & $5 \%$ & $30 \%$ & $3 \%$ & $14 \%$ \\
\hline \multirow{2}{*}{ Central Park, Nagoya } & area & 20,376 & 9308 & 256 & 8272 & 1260 & 1280 \\
\hline & $\%$ & $100 \%$ & $46 \%$ & $1 \%$ & $41 \%$ & $6 \%$ & $6 \%$ \\
\hline \multirow{2}{*}{ Kabuki, Tokyo } & area & 15,727 & 6884 & 0 & 4104 & 504 & 4235 \\
\hline & $\%$ & $100 \%$ & $44 \%$ & $0 \%$ & $26 \%$ & $3 \%$ & $27 \%$ \\
\hline \multirow[b]{2}{*}{ Botta, Yokohama } & area & 19,216 & 10,303 & 140 & 6485 & 480 & 1808 \\
\hline & $\%$ & $100 \%$ & $54 \%$ & $2 \%$ & $34 \%$ & $3 \%$ & $9 \%$ \\
\hline Average value (\%) & & $100 \%$ & $49 \%$ & $2 \%$ & $32 \%$ & $4 \%$ & $13 \%$ \\
\hline
\end{tabular}

Source: This table synthesizes a lot of information about Japanese underground streets published on the Internet, so it does not list all sources of information. 


\section{Development Value of Urban Underground Street}

Development and construction of underground streets in urban centers can solve many problems in the process of urbanization, such as land shortage, traffic congestion, disaster prevention and mitigation and so on. In addition, it can save the cost of urban construction and operation, meet the recreational needs of citizens and tourists, promote urban economic growth, improve the urban ecological environment and realize the urban sustainable development.

\subsection{Saving Land and Increasing Land Value}

Nowadays, people's increasing demand for material life and the gradual exhaustion of natural resources have become the main contradiction restricting the development of human society. The contradiction between people's demand for urban capacity and the lack of land resources is manifested. This is the so-called crisis of living space. In densely populated cities, the ground space is often superimposed, such as multi-storey overpasses. Many urban facilities are being built. The more densely populated the area, the more prominent the contradiction is, and the more expensive the land price is. Especially in the old urban areas, the way to solve this contradiction is to "develop underground space". The development and utilization of underground space can transfer some functions of the city from the ground to underground and realize the transformation from "two-dimensional" to "three-dimensional". It can improve the spatial utilization rate of urban land greatly and alleviate the contradiction between urban development and the shortage of land resources.

The development of underground space resources is almost infinite in theory. In the past ten years' research, the author has learned that the development of underground space within the depth of $30 \mathrm{~m}$ is equivalent to one third of the total urban area, which is equal to the volume of all urban ground buildings. In theory, the amount of underground space resources that a city can reasonably develop is $40 \%$ of the volume of the total urban land area multiplied by the reasonable development depth. If the reasonable development depth is $100-150 \mathrm{~m}$, when the average urban volume is $80 \%$, the urban space capacity can be expanded by 26 - 40 times, which will be a huge and rich space resource. Taking China as an example, the underground space resources of 337 major cities in China are 9 billion square meters, and the surface land area can be replaced by 8.8 million $\mathrm{mu}^{1}$ (Chang, 2017). Therefore, in the urban central area with inches of land and inches of gold, the rational development and construction of underground streets in a planned, step-by-step manner can increase a large amount of land resources without occupying arable land without expanding the size of the city, thus achieving the purpose of saving land.

\subsection{Relieving the Pressure of Urban Traffic}

With the continuous development of economy, people's demand for traffic is ${ }^{1} 1 \mathrm{mu}=666.67$ square meters. 
increasing day by day. With the increase of motor vehicles and the decrease of average road area, many problems have arisen in the city, such as traffic congestion, speed decline and environmental pollution. Underground street, as an effective form of human utilization of underground space, plays a very significant role in improving land use efficiency, alleviating ground traffic, improving human living environment, realizing three-dimensional diversion of pedestrians and vehicles, reducing the incidence of urban traffic accidents, reducing environmental pollution, and maintaining urban historical and cultural landscape. Its greatest advantage is that it does not occupy land on the ground, does not destroy the ground landscape and does not produce ground noise. It is an important development direction for modern city traffic guidance.

As people move underground, underground streets are beneficial to improving the traffic and environment on the ground. For areas where the weather is cold, snowy or hot and rainy, shopping underground is more popular with residents. Because of the development of metro and the enhanced accessibility of transportation, it can attract people to flow to this area, thus bringing new opportunities for urban commercial development and generating high profits. For example, in some big cities such as Sweden, Canada, West Germany, France, there are many underground streets and their benefits are quite good.

\subsection{Saving the Cost of Urban Construction}

At the beginning of the city, its development always extends along the two-dimensional direction. When the development of productivity and science and technology makes people can develop in the high altitude and underground, the city is on the track of comprehensive development along the three-dimensional direction. Urban underground space is a part of urban space resources, and its role and status in the city has been paid more and more attention by people. Its development and utilization make the city gather moderately and obtain the best economic benefits. Although the one-time investment in the development of underground streets is $3-4$ times as much as that in the construction of the same area on the ground, the maximum investment can reach 8-10 times. However, once the underground street is built, the cost of energy saving, operation and maintenance will be less than that of traditional over ground buildings. For example, heating and refrigeration in underground streets can save $1 / 3$ to $1 / 2$ of the cost of energy consumption compared with similar buildings on traditional floors.

\subsection{Meeting the Needs of Urban Recreation}

As a kind of recreational resources, underground streets are the direct motivation to attract foreign consumers to travel for leisure, shopping and tourism. Underground street is a blend of historical and cultural heritage and modern commercial culture, which condenses local customs and consumption pursuit. After natural selection and extension of time, underground street precipitated its 
unique cultural and commercial characteristics. These are precious tourist cultural resources, the most valuable tourist ornamental value, easy to arouse tourists' feelings of nostalgia and sighing for the present. The gradual improvement of underground street function reflects its recreational value more and more and strengthens the important role of underground street in booming urban economy and attracting tourists from all directions.

Urban underground streets have a strong attraction for consumers, because they are convenient and comfortable, not affected by external climate conditions. No matter whether the ground is windy or rainy or cold or hot, all recreational activities under the ground will not be affected. The development and utilization of underground streets can bring convenience to urban residents' commuting, entertainment and activities, and can bring shopping and leisure space for tourists.

Take Fukuoka, Japan as an example, Tenjin Underground Street, known as the largest underground street in Kyushu area, is divided into 12 streets, two 600 meters north-south commercial streets. Its business area is 11,400 square meters, with 153 stores, with an average daily flow of 400,000 people. It is the first scale in Kyushu and is also one of the countable underground streets in China. There are fashion clothing and personal stores, various delicacies, boutique stores, books and more than 150 stores in Tenjin Underground Street, which connect all the shopping malls on the ground at the same time. The scenery in the street is paved with stone pavements and crepe patterns, the ceiling of nineteenth Century European style. There are 600 stores in this street. There are plastic skylights covering the sun and rain. There are various restaurants on both sides. There are also clothing stores, grocery stores, vegetable and fruit stores, bookstores and so on. They sell a wide variety of goods, which make people unable to catch their eyes.

\subsection{Improving the Urban Ecological Environment}

The underground street has a certain constant temperature and heat preservation, and the energy consumption of underground buildings is obviously less than that of the ground buildings. The energy efficiency of underground buildings relative to the above ground buildings can reach $60 \%$, and the warehouse will reach $70 \%$. In addition, the unique thermal stability and closeness of underground streets are extremely beneficial to the storage of certain materials. To speed up the development and utilization of underground streets is a strong desire to create a livable environment. On the other hand, we should develop and utilize the underground streets, transfer all the facilities that can be transferred into underground, make a lot of ground for beautifying and greening the city, expand the open space of the city, promote the virtuous circle of the ecological environment, and create a fresh and beautiful livable environment. Boston, for example, demolished a six-lane viaduct across the city centre and built an 8 10-lane underground highway with the original ground turned into a shady road and a street park (Figure 5). 

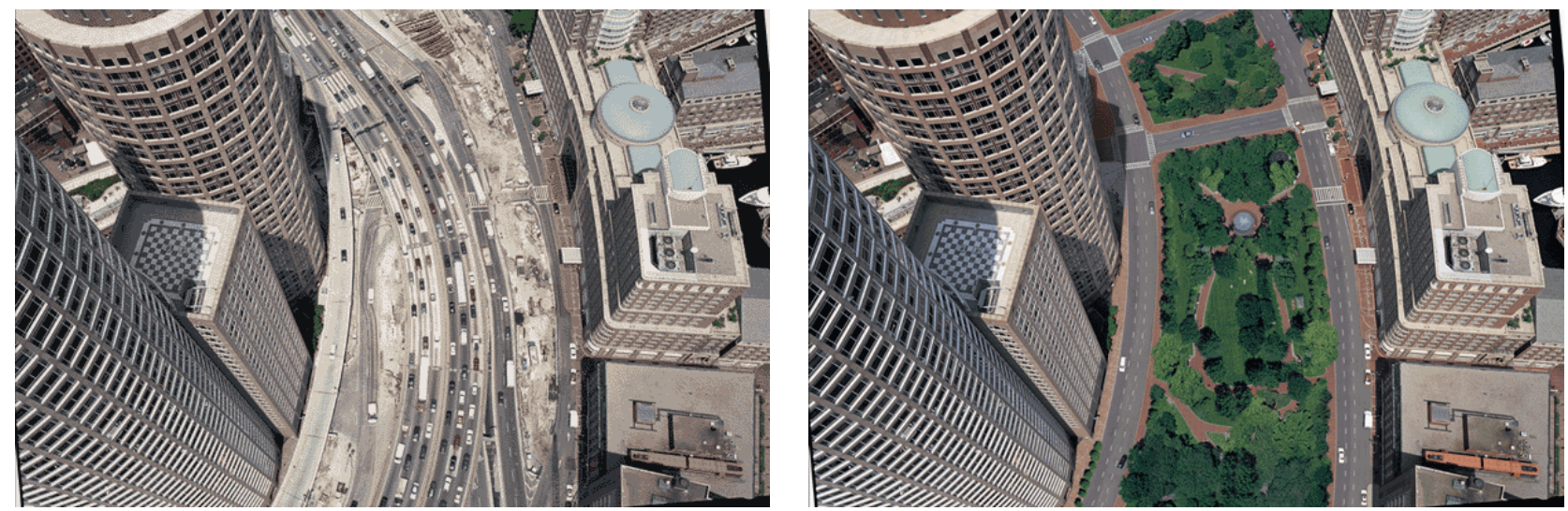

Figure 5. Comparison of Boston Street Park before and after renovation. Source: http://www.shijiebang.com/u60091/blog-19383/ (left: photo before renovation; right: photo after renovation).

\subsection{Enhancing the Ability of Urban Disaster Prevention and Mitigation}

Underground streets are generally more capable of defending against natural disasters than similar buildings on the ground. Storms and earthquakes have little or no impact on underground streets. If the underground streets are well handled, there is little chance of fire spreading, which is good for fire prevention and explosion protection. In cold weather, there is no problem of freezing and freezing pipes in underground streets. Underground streets are much lighter damaged by earthquakes than ground buildings under earthquake conditions. The acceleration of earthquakes over $30 \mathrm{~m}$ underground is only $40 \%$ of that at the surface. For example, in the 1976 Tangshan Earthquake in China, $40 \%$ of the urban population was killed, while in the underground civil air defense project (the underground street which did not have recreational function at that time), no casualties occurred. With the high density of modern cities and the high standardization of living standards, there are more and more supply facilities and pipeline construction of urban lifeline projects. If the cities combined with civil air defense project to build common ditch and underground street in urban center, it will help to reduce the repetitive excavation of roads and the impact of construction on traffic and urban residents' lives, facilitate maintenance, inspection and demolition, thus greatly improving the anti-destruction ability of urban infrastructure.

\section{Future Development Trend of Urban Underground Street}

\subsection{To Develop in 3 Dimensions (3Ds)}

The three-dimensional development model of urban development is an important means to solve various problems in the highly developed urbanization process. However, from the process of urban development in many developed countries, we have also summed up a lot of experience and lessons, the most important of which is that the three-dimensional model of upward development 
is not feasible. Due to the rapid development of urbanization and the shortage of land resources, skyscrapers have been built in urban central areas. Besides, to solve the traffic problems, elevated roads are also built. They worsen the environment of urban central areas gradually, and many residents and businesses choose to move out, resulting in the phenomenon of "anti-urbanization".

In recent years, people began to explore the potential and advantages of developing deep underground space. The development of underground space can not only protect the greening environment, historical environment and style of the ground, but also effectively solve the traffic pressure and make pedestrian system separate from vehicle system. Due to the early development of experience, Japan began to plan for underground development. They divide the development depth of underground space into very shallow depth to medium depth to large depth. At present, China stipulates that the first floor to the underground, the main branch line of the public utility pipeline network and the second floor to the underground of the common ditch shall be arranged, and the third floor to the underground streets, parking lots, subway stations and other entertainment facilities shall be arranged, as well as drainage ditches, underground garbage collection stations and three-dimensional underground parking lots.

\subsection{To Develop towards Commercial Complex}

With the continuous improvement of urban intensive degree, traditional single-function buildings cannot meet the requirements of the times, and commercial buildings are gradually moving towards the direction of multi-function and integration. Take Japan as an example, the early construction of underground street was around the two sides of the pedestrian road of the subway station, and a few basement buildings formed the underground space of Japan. After decades of development, nowadays the underground streets have gradually become one, and become a real underground business complex. In the future ideal city, the underground space should integrate the rail transit, public transport, subway, pedestrian and basement of buildings. People can travel conveniently, freely and quickly. The dazzling shops along the way are not only welcomed by consumers, but also bring unlimited profits to commercial investors. Together, they will form the perfect underground city commercial complex.

\subsection{To Develop toward Humanized Design}

In recent years, with the emergence of e-commerce, the offline retail industry has suffered tremendous impact, and more and more online sales platforms have replaced commercial entities. In 2015, Chinese department stores such as Yum Sheng and Martha continued to close on a large scale; McDonald's closed 80 stores in China, Wal-Mart closed $30 \%$ of its stores in China. The specific reasons for closing are various, but the impact of e-commerce led to a decline in performance is the main reason that the industry believes (Zhang, 2016). This situation 
directly led to the escalation of competition between offline businesses. Underground streets, as a new commercial form, are in the downside of competition due to various congenital limitations. Especially for the linear corridor underground street, there are some limitations in the shaping of the commercial space environment, and the lack of identification of the underground space can easily cause uncomfortable feelings to consumers. Therefore, only shaping the characteristic commercial space environment of underground street is the way of its sustainable development. Because it is an era of demand, creativity, culture and experience, people's life is no longer limited to meet basic needs, and begin to develop towards a higher level. It is the trend and requirement of the humanized development of underground streets in the future to create a new comprehensive place combining culture, commerce, recreation and sightseeing through different space design and management means to shape its own characteristics of serving users.

\subsection{To Develop toward Tourist Attractions}

In the future, the city will become a city shared by residents and tourists. Underground street is an important carrier of urban tourism development and will increasingly become a necessary place for tourists to travel to a city. It is a symbol of a city's tourism image and a beautiful business card in the city. Scenic spots are one of its major trends. In underground streets, tourist inquiry centers or tourist centers have become the necessary institutions for scenic spots, which has become more common in Japan, the United States and some European countries. In addition, it is no longer rare that tourist reception and service facilities such as travel agencies and hotels appear in underground streets. Underground streets will also develop together with other tourist attractions, share urban tourist resources and witness the development of urban tourism.

\section{Conclusion and Limitation}

This paper reviews the origin, classification, composition, development value and future trend of urban underground streets, which has important theoretical and practical guiding significance for the sustainable development of urban underground streets. The main conclusions of this paper are as follows: 1) Urban underground streets should keep reasonable proportional relationship among the business, transportation and supporting parts. Generally, the area of commercial use should not exceed 50\%. 2) Saving land, increasing land value, relieving the pressure of urban traffic are main developing value of urban underground street. 3) Future development trend of urban underground street is to develop in 3 Dimensions (3Ds), towards commercial complex, humanized design and tourist attractions. The limitation of this paper is that there is no quantitative analysis of the development value and development trend of underground streets, which needs time to collect large data and in-depth study in the future. 


\section{Conflicts of Interest}

The author declares no conflicts of interest regarding the publication of this paper.

\section{References}

Chang, Q. (2017). Urban Development: Great Potential for Underground Space. People's Daily (Chinese Edition), November 19th.

Gideon, S. G., \& Toshio, O. (1996). Geo-Space Urban Design (p. 66). New Jersey: John Wiley \& Sons.

Liu, C. Y., \& Shen, Y. H. (2007). Legal Research on Development and Utilization of Urban Underground Space in Japan. Chinese Journal of Underground Space and Engineering, 3, 587-591.

Tong, L. X. (2005). Underground Space and the Development of Urban Modernization (p. 57). Beijing: China Construction Industry Publishing House.

Zhang, X. L., \& Yao, L. (2016). Innovation of the Development Model of Offline Physical Stores under the Impact of E-Commerce-Based on the Comparison of Online and Offline Commercial Formats. Business Economic Research, No. 6, 127-129.

Zhou, Y., Tang, T. B. et al. (2006). Review and Prospect of Disaster Prevention and Mitigation in Urban Underground Space. Journal of Underground Space and Engineering, 2, 467-474. 